\title{
New and experimental approaches to back pain
}

\author{
Sean A. Kennedy, Mark O. Baerlocher MD
}

Most instances of low-back pain are nonspecific and resolve without intervention

A definitive cause cannot be determined in most patients with back pain, and most instances of back pain will resolve without treatment. The most common identifiable causes of persistent pain relate to nerve-root compression due to disc herniation, degenerative changes and vertebral compression fractures. ${ }^{1}$ In the absence of signs of complicated back pain (red flags), patients with nonspecific back pain can be managed with analgesia and physiotherapy. ${ }^{1}$

\section{Magnetic resonance imaging of the lumbar spine must be obtained in patients with complicated low-back pain}

The best initial radiologic investigation in complicated low-back pain, magnetic resonance imaging (MRI) is highly specific and sensitive for diagnosing most causes, including disc herniation, vertebral compression fractures and spinal stenosis. ${ }^{2}$ According to the American College of Radiology guidelines, patients with complicated low-back pain include those with a history of trauma, weight loss, cancer, corticosteroid use, focal neurologic deficits, age greater than 70 or duration of pain longer than six weeks. ${ }^{2}$ The presence of any of these red flags points to potentially important causes, including fracture, cancer and cauda equina syndrome. If MRI is contraindicated, computed tomography may still be useful. ${ }^{2}$
Novel techniques are being investigated for lumbar spine imaging in back pain

The most promising among these techniques is load-bearing MRI. Some studies have shown that degenerative changes in the spine are detected in a significantly higher proportion of patients when they are compressed axially in a supine position to simulate gravity than with conventional MRI. ${ }^{3}$ However, this technique is still investigational, and evidence is insufficient to support widespread adoption.

\section{Vertebroplasty can be used to treat painful, acute vertebral com- pression fractures}

Common causes of vertebral compression fractures include osteoporosis, metastatic cancer and trauma. Treatment options consist of conservative management with rest and analgesia, or vertebroplasty. ${ }^{4}$ During vertebroplasty, cement is injected into the vertebral body under fluoroscopic guidance to stabilize the fracture. In a randomized controlled trial comparing conservative management and vertebroplasty, pain at one year was significantly reduced among patients who received vertebroplasty (mean visual analog score 2.0, 95\% confidence interval 1.13-2.80, $p<0.001){ }^{4}$
Surgery and targeted injections can improve low-back pain due to disc herniation or facet joint arthritis

Disc herniation can result in nerveroot impingement. Discectomy or posterior decompression surgery is indicated for back pain with severe or progressive motor weakness or symptoms of cauda equina syndrome. For back pain related to nerve-root impingement without these features, selective nerve block can be performed, with the corresponding epidural space receiving a fluoroscopically guided steroid injection. ${ }^{1}$ Similarly, facet joint arthritis can be treated with injection of anesthetic and steroid, or alternatively, radiofrequency denervation or ablation. ${ }^{5}$ Both selective nerve block and facet joint injection typically result in immediate and substantial pain relief lasting several months; however, patients may need repeated injections. Complications are rare and include dural puncture and nerve injury. ${ }^{5}$

For references, please see Appendix 1, available at www.cmaj.ca/lookup/suppl /doi:10.1503/cmaj.130640/-/DC1

Competing interests: None declared.

This article has been peer reviewed.

Affiliations: School of Medicine (Kennedy), McMaster University, Hamilton, Ont.; Department of Radiology (Baerlocher), Royal Victoria Hospital, Barrie, Ont.

Correspondence to: Sean Kennedy, sean.kennedy @ medportal.ca

CMAJ 2014. DOI:10.1503/cmaj.130640 